\title{
Can We Predict ACL Hamstring Graft Sizes in the Asian Male? A Clinical Relationship Study of Anthropometric Features and 4-Strand Hamstring Graft Sizes
}

\author{
WL Loo, MMed (Ortho), BYE Liu, MRCS (Edin), YHD Lee, FRCS (Ortho), YHM Soon, FRCS (Ortho) \\ Department of Orthopaedic Surgery, Alexandra Hospital, Singapore
}

\begin{abstract}
Introduction: This study was undertaken to investigate if such anthropometric measurements (i.e., height, weight and body mass index) can be used to predict graft diameters in 4 strand semitendinosus and gracilis hamstring autografts. Methods: The study sample consisted of 89 consecutive male patients who underwent ACL reconstruction using quadrupled semitendinosus and gracilis autografts. Intraoperative measurements of the fashioned quadrupled hamstring graft were performed using sizing tubes calibrated to $0.5 \mathrm{~mm}$. Correlation coefficients (Pearson $\mathrm{r}$ ) analysis was used to determine the relationship between hamstring graft diameter and predictor variables: gender, height, mass, and body mass index. Results: The mean hamstring graft diameter, $7.90 \mathrm{~mm}$, was comparable with previously published studies. Weight $(\mathrm{r}=0.18)$ and body mass index $(r=0.19)$ correlated positively with graft diameter. There was no correlation between graft diameter and height $(\mathrm{r}=0.01)$. Conclusion: In Asian male patients, height, weight and BMI cannot be used for preoperative identification of graft size.
\end{abstract}

Key Words:

Anterior cruciate ligament reconstruction; arthroscopy; hamstring graft; anthropometry

\section{INTRODUCTION}

Anterior cruciate ligament (ACL) reconstruction has become an exceedingly common procedure performed by orthopaedic surgeons over the past 20 years ${ }^{1,2}$. The quadrupled hamstring tendon autograft is used with increasing frequency in ACL reconstruction based on its favourable biomechanical profile and positive clinical outcomes ${ }^{3,4}$.

Biomechanical studies have established that the load at which failure occurs in a hamstring graft is proportional to its diameter. Further studies have shown that factors such as gender, height, weight, body mass index and femur length correlate with the diameter of the quadrupled hamstring autograft. This information may be useful during preoperative discussion with patients who have factors predictive of a need for smaller graft diameter, so that alternate graft sources may be considered when appropriate. To our knowledge, there is little in the literature correlating anthropometric measurements and hamstring graft diameter in the Asian male. We hypothesized that anthropometric measurements such as height, weight and body mass index can be used to predict graft diameters in 4 strand semitendinosus and gracilis hamstring autografts in the Asian male.

\section{MATERIALS AND METHODS}

We reviewed the records of 89 consecutive Asian male patients who underwent primary ACL reconstruction using a 4 strand semitendinosus and gracilis autograft from September 2007 to February 2008. Multiligamentous injuries were included although they comprised a minority of patients in this sample. The majority of the patient population consisted of young adult males who sustained the injury during sports or military training. All ACL reconstructions using single hamstring tendon quadrupled to a 4 strand graft were excluded from this study. Six female patients who underwent ACL reconstruction during this study period were also omitted from the study.

For all included patients, the height, mass and calculated body mass index were noted. All measurements were recorded on a scale by clinical staff. None of these measurements were self-reported. All patients underwent ACL reconstruction using standard graft harvesting and preparation technique practiced by the surgeons at our institution.

The hamstring tendon autograft was harvested at the pes anserinus using a longitudinal anteromedial incision. The semitendinosus and gracilis tendons were harvested separately using a metal tendon stripper, after ensuring that the fascial attachments and accessory attachments were divided.

The graft was then cleaned of adherent muscle fibres, folded over once creating four strands; the strands were then 
Table I: Means \pm Standard Deviations of Demographic Data Used for Current Analyses of Hamstring Tendon Diameter

\begin{tabular}{|lccccc|}
\hline & Age & Height (metres) & Weight $(\mathbf{k g})$ & Body mass index & Graft diameter $(\mathrm{mm})$ \\
\hline Male & $23.9 \pm 5.9$ & $1.71 \pm 0.05$ & $70.0 \pm 11.9$ & $23.7 \pm 3.4$ & $7.90 \pm 0.74$ \\
\hline
\end{tabular}

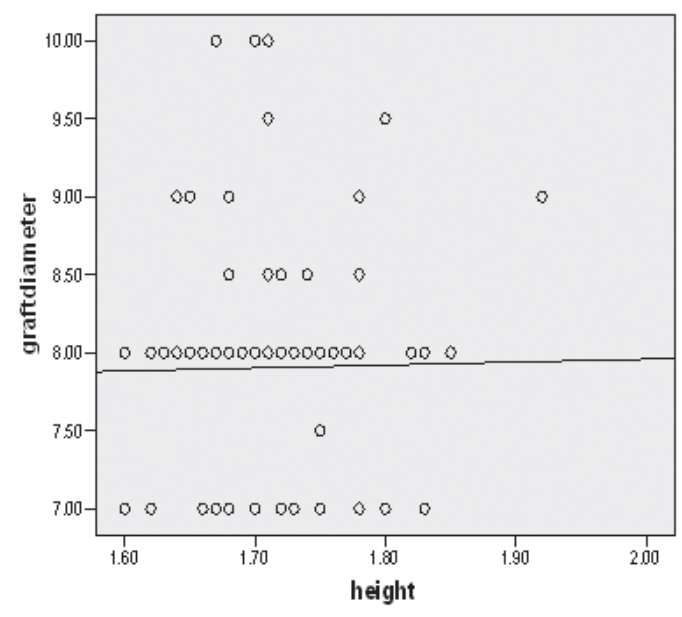

Fig. 1: Correlation between graft diameterand height $(r=0.015)$.

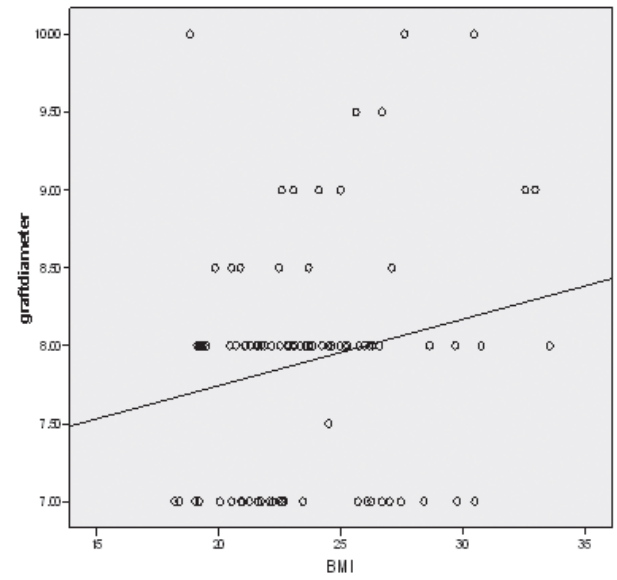

Fig. 3: Correlation between graft diameter and BMI $(r=0.19)$.

stitched together using Ethibond 5.0 sutures with a standard whip stitch technique. The prepared grafts were sized with calibrated sizing cylinders (Arthrex Inc., Naples, Florida) with the folded end first. All grafts used were of a minimum of $100 \mathrm{~mm}$ "total graft length" after final preparation.

Statistical analysis was performed using SPSS (Version 11.0, SPSS Inc, Chicago, IL). The relationship between the hamstring graft diameter and the variables: age, gender, height, mass and body mass index were analyzed utilizing the Pearson $r$ correlation coefficient.

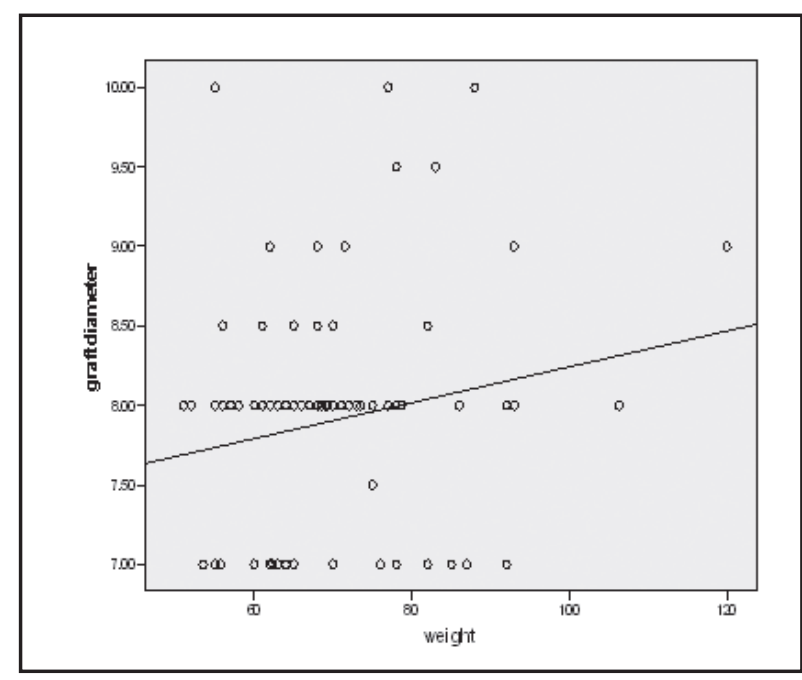

Fig. 2: Correlation between graft diameter and body weight $(r=0.18)$.

\section{RESULTS}

In the 89 male patients, the mean 4-strand hamstring graft size was $7.90(+/-0.749) \mathrm{mm}$ (Table 1). Graft size frequencies among the data were as follows: $7 \mathrm{~mm}(29.2 \%)$, $7.5 \mathrm{~mm}(1 \%), 8 \mathrm{~mm}(50.5 \%), 9 \mathrm{~mm}(13.5 \%)$, and $10 \mathrm{~mm}$ $(5.6 \%)$. Weight $(\mathrm{r}=0.18, \mathrm{p}=0.05)$ and body mass index $(\mathrm{r}=0.19, \mathrm{p}=0.04)$ were only weakly correlated with graft diameter. There was no correlation between graft diameter and height $(\mathrm{r}=0.01, \mathrm{p}=0.66)$.

\section{DISCUSSION}

Recent studies have shown an increased incidence of anterior knee pain, arthrofibrosis, and quadriceps weakness associated with use of the bone-patellar tendon-bone autograft ${ }^{5,6}$. In addition, the 4-strand hamstring tendon graft has been demonstrated to be stronger and stiffer than the bone-patellar tendon-bone graft. As a result, there has been a paradigm shift and the 4 strand graft is now used with increasing frequency.

The biomechanical strength of the 4 strand graft is approximately $250 \%$ greater than that of the native $\mathrm{ACL}^{7-10}$. However, grafts with smaller diameters may be weaker than this, which may potentially compromise graft integrity and ultimately clinical outcome. The ability to predict which patients have relatively small hamstring tendons may be beneficial to the surgeon, in that alternate graft sources may then be considered when appropriate. 
In a cadaveric study, Tan et al reported that the anterior cruciate ligament in the Singapore Chinese was smaller than those reported in the Western literature ${ }^{11}$. Based on this observation, one may speculate that the hamstring tendons in the current sample would be smaller compared to Caucasian patients as well. However, in our cohort of Asian patients, the 4 strand hamstring graft size frequencies and mean graft diameter in this study were similar to reports from Western counterparts. In the Western literature, the mean graft sizes for 4-strand hamstring grafts range from 7.9 to $8.6 \mathrm{~mm}$ for males ${ }^{12,13}$, and our results showed that the mean hamstring graft diameter was $7.9 \mathrm{~mm}$ (Table 1).

Tuman showed that height is the best predictor among anthropometric data in hamstring graft size ${ }^{12}$. In his study, BMI did not appear to accurately predict hamstring graft diameter, leading to his recommendation not to rely upon BMI before harvest. Pichler, in a cadaver study, found a correlation between the cross-sectional area of the semitendinosus and gracilis tendons and the length of the femur, which also correlated to height ${ }^{13}$.

Results of the current study show that weight and BMI did not correlate to graft diameter. However, it should be noted that there are several limitations in our study. There may be interobserver variation in graft measurement, as this study cohort was comprised of patients treated by different consultant surgeons who sized the graft themselves. Further, the sample size used here is relatively small, so our results may not be representative of the Asian male, which is a relatively non-homogenous group.

Nevertheless, we concluded that anthropometric measurements such as height, weight and BMI cannot be used as definitive predictors for the hamstring graft diameter during harvest. In short-statured or underweight patients undergoing ACL reconstruction, alternative graft sources should be considered preoperatively. Future studies should include measurements like quadriceps strength, thigh circumference, limb length, and athlete activity level to determine if they are correlated with graft size.

\section{CONCLUSION}

In the Asian male patient undergoing anterior cruciate ligament reconstruction, anthropometric measurements like height, weight and BMI cannot be depended upon for preoperative identification of patients at risk for smaller hamstring graft size. 


\section{REFERENCES}

1. Lipscomb AB, Johnston RK, Snyder RB, et al: Evaluation of hamstring muscle strength following use of semitendinosus and gracilis tendons to reconstruct the anterior cruciate ligament. Am J Sports Med. 1982; 10: 340-2.

2. Otero AL, Hutcheson L: A comparison of the doubled semitendinosus/gracilis and central third of the patellar tendon autografts in arthroscopic anterior cruciate ligament reconstruction. Arthroscopy. 1993; 9: 143-18.

3. Mott HW: Semitendinosus anatomic reconstruction for cruciate ligament insufficiency. Clin Orthop 1983; 172: 90-2.

4. Marder RA, Rasking JR, Carroll M; Prospective evaluation of arthroscopically assisted anterior Cruciate Ligament Reconstruction, Patellar Tendon vs Semitendinosus and Gracilus Tendons. Am J Sports Med. 1991; 19(5): 478-84.

5. Otto D, Pinczewski LA, Clingeleffer A, et al: Five-year results of single incision arthroscopic anterior cruciate ligament reconstruction with patellar tendon autograft. Am J Sports Med. 1998; 26: 181-8.

6. Shelbourne KD, Gray T: Anterior cruciate ligament reconstruction with autogenous patellar tendon graft followed by accelerated rehabilitation. A two- to nine-year followup. Am J Sports Med. 1997; 25: 786-95.

7. Noyes FR, Butler DL, Grood ES, Zernicke RF, Hefzy MS; Biomechanical Analysis of Human Ligament Grafts Used In Knee Ligament Repairs and Reconstructions. J Bone Joint Surg. 1984; 66A (3); 344-52.

8. Woo SL, Hollis JM, Adams DJ, Lyon RM, Takai S. Tensile properties of the human femur-anterior cruciate ligament-tibia complex. The effects of specimen age and orientation. Am J Sports Med. 1991; 19(3): 217-25.

9. Hamner DL, Brown CH Jr, Steiner ME, Hecker AT, Hayes WC. Hamstring tendon grafts for reconstruction of the anterior cruciate ligament: biomechanical evaluation of the use of multiple strands and tensioning techniques. J Bone Joint Surg Am. 1999; 81(4): 549-57.

10. Woo SLY, Wu C, Dede O, Vercillo F, Noorani S. Biomechanics and anterior cruciate ligament reconstruction. J Orthop Surg. 2006; $1: 2$.

11. Tan JL, Chang PCC, Mitra AK, Tay BK. Anthropometry of anterior cruciate ligament in Singapore Chinese. Ann Acad Med Singapore 1998; 27: 776-9.

12. Tuman JM, Diduch, DR, Rubino LJ, Baumfeld JA, Nguyen HS, Hart JM. Predictors for hamstring graft diameter in anterior cruciate ligament reconstruction. Am J Sports Med. 2007; 35: 1945-9.

13. Pichler W, Tesch NP, Schwantzer G, Fronhofer G, Boldin C, Hausleitner L, Grechenig W. Differences in length and cross-section of semitendinosus and gracilis tendons and their effect on anterior cruciate ligament reconstruction. J Bone Joint Surg (Br) 2008; 90-B: 516-19. 